\title{
Left Internal Mammary Artery to Left Anterior Descending Artery. An Alternative for old, High-Risk, Multivessel, Coronary Artery Disease Patients and an Approach for Hybrid Revascularization
}

\author{
Federico Benetti ${ }^{1 *}$, Jessica Gonzalez ${ }^{1}$, Natalia Scialacomo ${ }^{1}$ \\ ${ }^{1}$ Benetti Foundation Alem 1846 Rosario Argentina CP 2000
}

*Corresponding Author: Federico Benetti, Fundacion Benetti Alem 1846 Rosario Argentina CP 2000.

Received Date: October 18, 2021; Accepted Date: December 22, 2021; Published Date: January 03,2022

Citation: Federico Benetti, Jessica Gonzalez, Natalia Scialacomo (2022). Left Internal Mammary Artery to Left Anterior Descending Artery. An Alternative for old, High-Risk, Multivessel, Coronary Artery Disease Patients and an Approach for Hybrid Revascularization. J. Clinical Cardiology and Cardiovascular Interventions, 5(1); Doi:10.31579/2641-0419/230

Copyright: (C) 2022 Federico Benetti, This is an open-access article distributed under the terms of the Creative Commons Attribution License, which permits unrestricted use, distribution, and reproduction in any medium, provided the original author and source are credited.

\begin{abstract}
In 1997, the first ambulatory off-pump left internal mammary artery (LIMA) to left anterior descending artery (LAD) anastomosis was performed via xiphoid approach, an intervention known today as the MINI-OPCAB operation. This operation has been performed in more than 150 patients around the world for the management of single and multiple vessel coronary artery disease, and 70 of those cases underwent the procedure in our Foundation from 1997 to 2021 , showing no operative mortality or reintervention rates, low conversion rates, early hospital discharge, and $100 \%$ graft patency at the follow-ups.

The minimally invasive direct coronary artery bypass (MIDCAB) procedure was introduced in 1994 by Benetti from Argentina, and was developed based on our previous experience performing off-pump coronary surgery by manipulating the ascending aorta through a left-sided small thoracotomy. Although it represents one of the most common minimally invasive procedures done worldwide, the original technique is not easy to reproduce, and in most cases the pleura is opened, which increases patients pain, morbidity, hospital length of stay, and hinders the realization of immediate hybrid revascularization after the procedure.

The latest minimally invasive approaches for CABG include robotic-assisted procedures, in which the IMAs are harvested using robotic technology or the whole procedure is done using robotic technology. This approach has shown adequate short-term clinical results, however, there are no studies available reporting the procedure's long-term results.

Conclusion: The MINI-OPCAB operation is a friendly approach to perform Minimally Invasive Coronary Bypass Surgery in old, high-risk, multivessel coronary artery disease patients, and it represents a good intervention alternative for the majority of cardiac surgeons and cardiac specialized centers. We also consider this approach as ideal for patients who further require Hybrid Revascularization; however, more experience is needed to validate this initials results.

Key Words: minimally invasive coronary surgery; coronary surgery; robotic coronary; hybrid revascularization; hight risk coronary
\end{abstract}

\section{Introduction}

In 1997, the first ambulatory off-pump left internal mammary artery (LIMA) to left anterior descending artery (LAD) anastomosis was performed via xiphoid approach (xiphoid lower sternotomy incision) using three-dimensional video technology in a patient with a long xiphoid appendix. [1-4] In the Mini Off-Pump Coronary Artery Bypass Surgery
(MINI-OPCAB) an incision is made over the sternum to the level of the third or fourth intercostal space (according to the patient anatomy), a retractor is placed to ensure proper visualization of the left mammary artery, and around $8 \mathrm{cms}$ of the left mammary artery are dissected, skeletonized and clamped making sure the angle where the artery is still attached to the sternum is below 20 degrees to avoid potential kinking. $[1,4]$ Then, the pericardium is opened from the left border of the 
pulmonary artery towards the apex of the heart to visualize the LAD and define the potential site of anastomosis, the patient is heparinized, the LAD is occluded with 5-0 Prolene, a mechanical stabilizer is positioned in the beating heart to permit a steady incision and stitching, and the LIMA-LAD anastomosis is performed. [1,4] After ensuring an adequate blood flow, pulsatility and resistance index on the graft with the MediStim System, the mammary artery is fixed with two 7-0 Prolene stitches in both sides at $1 \mathrm{~cm}$ from the anastomosis, drains are placed avoiding contact with the graft, and the sternum is closed using one or two wires. [1,4]

\section{Material and Methods}

We have done the MINI-OPCAB operation for single and multiple diseased vessels in more than 150 patients in different centers around the World; [5] of these cases, 70 patients underwent MINI-OPCAB operation with LIMA-LAD bypass from 1997 to 2021 in our Foundation, and 10 of them received concomitant hybrid revascularization. The mean age of the patients was 67 years, $23(33 \%)$ had triple vessels disease, $18(26 \%)$ had double vessels disease, 26 (37\%) had single-vessel disease, and $3(4 \%)$ had severe left main disease. From their past medical history, 27 (39\%) had previous myocardial infarction, 12 (17\%) had previous catheterization, and $4(6 \%)$ had previous coronary artery bypass surgery. The mean Euro Score preoperative risk on these population was 3.5. [3]

\section{Results}

There was no operative mortality reported, 1 (4\%) patient required conversion to midline sternotomy, the reintervention rate was $0 \%, 55$ (79\%) patients were extubated in the operating room, and the mean length of hospital stay was 60 hours. During the follow-up, 16 patients with LIMA-LAD were restudied showing $100 \%$ patency of the grafts, and at 144 months $82 \%$ of the patients were alive from which $68 \%$ were asymptomatic. [1,6] Furthermore, a prospective study done at our foundation evaluating the MINI-OPCAB approach in high-risk patients with multivessel coronary artery disease that received LIMA- to LAD only plus medical treatment showed that from the 14 patients enrolled, with a mean age of 71 years and a preoperative Logistic Euro Score of 10.68 , there was no operative mortality reported, the average operating time was 2 hours and 20 minutes, the mean length of hospitalization was 2 days, the rate of major adverse cardiac events was $0 \%$ and one patient died at 85 years due to a stroke ( 5 years after the intervention)

\section{Discussion}

Some of the benefits of this technique are that: it is simpler than the traditional $\mathrm{CABG}$; it allows converting the operation, if necessary, by extending the sternotomy incision; an adequate mammary harvesting, skeletonization and blood flow and resistance measurement can be easily done to ensure the quality of the anastomosis; there is lower risk as the aorta is not manipulated; and preserving the upper sternum allows for future interventions on the aortic valve. [7] Also, this approach is ideal for candidates to hybrid revascularization, as patients tend to tolerate very well the procedure and can be transported to the catheterization lab and undergo stenting immediately following the MINI-OPCAB surgery.

Among other minimally invasive approaches, there is the minimally invasive direct coronary artery bypass (MIDCAB), introduced in 1994 by Benetti [8-14] from Argentina. This operation was developed based in our previous experience doing off-pump coronary surgery in single and multiple vessels with mammary arteries and vein grafts manipulating the ascending aorta for the proximal anastomosis through a left-sided small thoracotomy. [15] Nowadays, for immobilization and exposure of the target vessels we are using different suction or pressure stabilizers and positioners which have been developed based in our own and others' original inventions. [16-18] after an adequate stabilization technique, anastomoses are carried out with local coronary artery occlusion.
The first MIDCAB cases we did were done with the use of thoracoscopy and without opening the pleural cavity, addressing either single or multiple vessels. However, the original technique, that was ideal for an enhanced recovery of the patients, is not easy to reproduce, and, in the majority of cases, the pleura is opened, which increases the patients' postoperative pain and need for intravenous narcotics, requires the placement of a left pleural tube that may impair the patients' mobility, hinders the hybrid approach as it increases the time between the surgery and stent placement, and increases the likelihood of postoperative complications such as pneumothorax and pleural effusion. Furthermore, when comparing the hospital length of stay, none of the first MIDCAB cases done at our Foundation was discharged in the first 24 hours, compared to the first case of MINI-OPCAB (also done at the Foundation) that was discharged 22 hours after the procedure.

The latest minimally invasive approaches for CABG include roboticassisted procedures, such as the Robotically assisted coronary bypass grafting through mini-thoracotomy and the Robotically assisted totally endoscopic coronary artery bypass (TECAB). In this version of minimally invasive surgery, the internal mammary arteries (IMAs) are harvested using robotic technology and the grafts to the coronary arteries are done through a left-sided mini-thoracotomy or the whole procedure (IMA harvesting, pericardiotomy and graft anastomoses) is done using robotic technology. Since the first robotic TECAB surgery in 1998 by Loulmet and coworkers, [19] a total of 1,678 cases were identified in the cardiac surgery literature.

A recent review done by Bonatti $\mathrm{J}$ et al. [20], reviewing a total of 74 patient series published between 1996 and 2019, shows that $27.8 \%$ of the reported robotic-assisted procedures represent multivessel CABGs. In this review, the operative times reached $5.3 \pm 0.8$ hours, the cumulative conversion rate was $10.3 \%$, the perioperative mortality reached $1.3 \%$, the mean length of hospital stay was $5.2 \pm 1.6$ days, and the 3 -year survival was reported in 2 papers as $96 \%$ and $95.5 \%$. [20,21] This approach has shown adequate short-term clinical results and represents the minimally invasive technique with the least tissue trauma; however, there are no studies available reporting the procedure's long-term results, procedure times are usually longer than the other presented techniques, the learning curve has shown to require a triple-digit number of repetitions for the surgeon and team to achieve a comfort level demanding long training sessions, and it is a procedure dependent on complex technology with limited access and high costs for the moment [20,21]

\section{Conclusions}

The MINI-OPCAB operation is a friendly approach to perform Minimally Invasive Coronary Bypass Surgery in old, high-risk, multivessel coronary artery disease patients, and it represents a good intervention alternative for the majority of cardiac surgeons and cardiac specialized centers. We also consider this approach as ideal for patients who further require Hybrid Revascularization; however, more experience is needed to validate this initials results.

\section{Funding: NONE}

\section{Conflict of interest:}

Federico Benetti MD have a patent pending for a Retractor for the MINI OPCAB operation

Jessica Gonzalez MD and Natalia Scialacomo MD don't have any conflict of interest

\section{References:}

1. Benetti FJ. Minimally invasive coronary surgery (the xiphoid approach). Eur J Cardio-Thoracic Surg. 1999;16(Suppl 2):S10S11. 
2. Benetti,F J Xiphoid access for cardiac surgical procedures US Patent 6199556B1 2004

3. Lima, R., \& Benetti, F. (2020). Early and long-term clinical outcome after minimally invasive direct coronary bypass grafting versus off-pump coronary surgery via sternotomy. Journal of Cardiac Surgery, 35(12), 3420-3421

4. Federico j Benetti et al MINI OPCAB Operation Surgical Technique Surg Technol Int Mar 23,38/1400 Online ahead of print

5. Benetti F, et al Xiphoid lower-sternotomy approach for multivessel revascularization of the left internal mammary artery to the left anterior descending artery and right internal mammary artery inflow to the other vessels. Heart Surg Forum. 2010 Feb;13(1):E36-9. doi: 10.1532/HSF98.20091131

6. Benetti, F.J. (2010) MINI-Off-Pump Coronary Artery Bypass Graft: Long-Term Results. Future Cardiology, 6, 791-795

7. Benetti FJ eComment ; Increase the Surgical Options Interactive Cardiovascular and Thoracic Surgery 7(4):707,doi:10.1510/icvts.2008.182790A

8. Benetti FJ. Uso de la toracoscopia en cirugía coronaria para disección de la arteria mamaria interna. Prensa Med Argent 1994;81:877-879.

9. Benetti F. J., Ballester C. Use of thoracospopy and a minimal thoracotomy, in mammary-coronary bypass to left anterior descending artery, without extracorporeal circulation, Journal of Cardiovascular Surgery 1995; 36:159-161

10. Benetti F. J., Ballester C. Coronary revascularization with arterial conducts via small thoracotomy and assisted by thoracoscopy although without cardiopulmonary bypass. Cor- European 4 (1) 22-24 (1995) Ecomedpublishers, d-86899 LandsbeneGermany.

11. Benetti F. J., Ballester C. Sani G, Boonstra P, Grandjean J. Video Assisted Coronary Bypass Surgery. Journal of Cardiovascular Surgery 1995; 10:620-625.
12. Benetti F. J., Ballester C. Coronary revascularization with the arterial conduits via a small thoracotomy and assisted by thorascopy, although without cardiopulmonary bypass. Coronary Revascularization 1995; 4(1):22-24.

13. Benetti F. Mariani M. A., Sani G. et al. Video-assisted minimally invasive coronary operations without cardiopulmonary bypass: a multicenter study. Journal of Thoracic and Cardiovascular Surgery. 1996; 112(6):1478-1484.

14. Federico Benetti : Method for coronary bypass United States Patent Patent N 5,888,247

15. Benetti, FJ., et al. Direct myocardial revascularization without extracorporeal Circulation experience in 700 patients. "Chest" Vol. 100/2, pag 313 (Aug 1991)

16. Benetti et al Surgical Method for stabilizing the beating heart during coronary artery bypass graft surgery United States Patent N 5,894,843

17. Benetti et al Surgical devices for imposing a negative pressure to fix the position of cardiac Tissue during surgery United states Patent N 5,727,56

18. Benetti et al Access platform for internal mammary dissection. United states Patent n 5730757A

19. Loulmet D, Carpentier A, d'Attellis N, et al. Endoscopic coronary artery bypass grafting with the aid of robotic assisted instruments. J Thorac Cardiovasc Surg 1999;118:4-10.

20. Bonatti, J., Wallner, S., Crailsheim, I., Grabenwöger, M., \& Winkler, B. (2021). Minimally invasive and robotic coronary artery bypass grafting - a 25-year review. Journal of Thoracic Disease, 13(3), p 1922.

21. Cheng N, Gao C, Yang M, et al. Analysis of the learning curve for beating heart, totally endoscopic, coronary artery bypass grafting. J Thorac Cardiovasc Surg 2014;148:1832-1836.

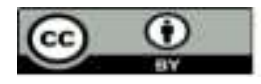

This work is licensed under Creative Commons Attribution 4.0 License

To Submit Your Article Click Here: Submit Manuscript
Ready to submit your research? Choose Auctores and benefit from:

$>$ fast, convenient online submission

$>$ rigorous peer review by experienced research in your field

$>$ rapid publication on acceptance

$>$ authors retain copyrights

$>$ unique DOI for all articles

$>$ immediate, unrestricted online access

At Auctores, research is always in progress.

Learn more https://auctoresonline.org/journals/clinical-cardiology-andcardiovascular-interventions 